\title{
Ischaemic lacunae in the spinal cord of arteriosclerotic subjects
}

\author{
C. Fieschi, A. GOTtlieb, AND V. DE CAROLis \\ From the Istituto di Clinica delle Malattie Nervose é Mentali dell'Universita' di Genova, Italy
}

Garcin and Gruner in 1953 and Neumayer in 1955 described in the anterior horns of the spinal cord of atherosclerotic subjects small necrotic patches which they considered as ischaemic foci due to atherosclerotic occlusion of spinal arteries. The related clinical picture, similar to that defined as 'téphromalacie antérieure' by Marie and Foix (1912) bore resemblance to amyotrophic lateral sclerosis, consisting of a combination of symptoms of upper and lower motor neurone involvement. On the basis of an extensive anatomo-clinical study, Neumayer (1955), Neumayer (1962), and Jellinger (1966) on several occasions stressed the importance of 'vascular myelopathy in old age', which, from a clinical standpoint, they subdivide into three groups: (1) syndrome of nuclear amyotrophy; (2) syndrome of spastic spinal paralysis; (3) syndrome of incomplete transverse section.

The first and by far the most frequent of these syndromes seems in fact that of nuclear amyotrophy, which was observed by these authors in 77 out of 85 cases and consisted of wasting and weakness of the small muscles of the hand, and scattered pyramidal tract signs. The syndrome begins late in life (after 65 years of age), develops slowly, and runs a progressive course during which it may show signs of bulbar involvement.

The anatomical counterpart consists of necroses with rarefaction (Rarifikationnekrose) of the centre of the anterior horns, mainly at the level of the cervical enlargement. Degenerative changes may be of various degree, from simple atrophy and spongy dissolution to actual 'cavitary' necrosis; glial reaction is always poor. The white matter may also be affected, showing a marginal or deep demyelination of the posterior or lateral columns.

That these changes are produced by chronic ischaemia seems attested to by concurrent severe arteriosclerotic aortic alterations and by the fact that the transverse location of the lesions corresponds to the area supplied by the terminal branches of the central arteries (Jellinger and Neumayer, 1962). Should these inferences be correct, one would rightly expect to meet fairly frequently with similar $\frac{\frac{\partial}{\bar{\rho}}}{2}$ even though less advanced, alterations in the spina 8 cord of elderly subjects with generalized atherogy sclerotic involvement. This would add further support to the above-mentioned pathophysiologica $P$ interpretation.

The aim of the present research is a systematio and accurate examination of the spinal cord of elderly atherosclerotic subjects to verify the existence and features of possible ischaemic changes.

The literature does not provide exhausti data on this subject; in fact, grey matier lesiक्षि of this type are not described in the classic anatomiapo studies on the spinal cord lesions associated woth atherosclerosis; attention was directed rather $\vec{T} \vec{Q}$ alterations in the white matter (Demange, 1884 Dejerine, 1906; Lhermite, 1907; Guizzetti, 19\%4 Lanza, 1938; Bailey, 1953; Fazio, 1969).

Only recently Mannen (1963), in a systema्tio examination of macroscopic sections of the spinat cord of 300 unselected elderly subjects, observe? 25 small circumscribed softenings of the grey matter particularly in the anterior horns. These softened foci were more frequent at the level of C5 to C6D In most patients no symptoms had appeared through out life.

Our case material is composed of 10 elderl subjects with severe generalized arteriosclerotic lesions, particularly at the level of the aorta, who: died from cerebral ischaemic lesions. In each case we noted the frequency, the morphological features? location, and extent of the spinal ischaemic lesions and considered the possible relationship betweet their sites and the disposition of the afferent arteria@ branches (the latter, as we know, vary within wide limits in different cases; Sarteschi and Giannini응 1960; Bartsch, 1961; Corbin, 1961). Finally, we tried to establish a relationship between the presence. of such lesions and the degrees of arteriosclerotiou change in the intra- and extraspinal vessel network

Part of this material has been illustrated in previous note (Fieschi and De Carolis, 1962 N Fieschi and Gottlieb, 1967). 


\section{MATERIAL AND METHOD}

The spinal cord of 10 subjects aged from 62 to 82 , who died after acute ischaemic cerebrovascular insults, was removed. Only the undamaged stretch of cord was examined: for this reason only the cervical enlargement could be examined in four cases. In the remaining six cases the study refers only to dorsal, lumbar, and sacral segments.

The spinal cord was removed with all its coverings. After fixing in $10 \%$ formalin we opened the dura mater lengthwise both anteiciorly and posteriorly and noted the number, position, and calibre of the radicular vessels and of the anterior spinal artery at various levels. Anterior and posterior spinal roots were numbered and included in paraffin, sectioned, and stained with haematoxylin-eosin and with van Gieson and Weigert's methods for elastic fibres. In this way we could ascertain the position and number of the radicular arteries that were 'efficient'-that is, delivering a satisfactory blood flow to the spinal cord, at the same time evaluating the degree of arteriosclerotic changes.

The spinal cord was cut transversely and each spinal segment included was cut to $10 \mu$ thick sections in semi-seriation (five consecutive sections every 15, mounted on separate slides). Two of the five series of slides thus obtained were stained with haematoxylineosin and with Weil's method, the other three being kept for control and further staining (van Gieson, Nissl, Weigert) which might have proved suitable in the course of the research.

In each segment we took into account (1) the calibre and mural alterations of both anterior and posterior spinal arteries; (2) alterations of intraspinal arteries; (3) alterations of the nervous tissue.

\section{DESCRIPTION OF CASES}

CASE 1 G.A., aged 62 years, was a diabetic man who suffered from a sudden left hemiplegia and exhibited electrocardiographic signs of myocardial infarction and atrial fibrillation. Right carotid angiography showed occlusion of the horizontal tract of the middle cerebral artery. He died on the third day from cardiocirculatory failure after slow progressive worsening of symptoms.

Pathological data (Necropsy no. 17397) Necropsy revealed serious generalized atherosclerosis, mainly aortic and coronary, myocardial infarction, hypertrophy and dilatation of the heart; and atherosclerosis of the arteries of the circle of Willis with thrombosis of the right middle cerebral artery. There was right frontoparieto-occipital haemorrhagic softening, atrophy of pancreas, and bilateral bronchopneumonia.

The spinal cord was examined from D2 downwards.

Radicular arteries Two anterior ones were found, the first at D6, the other at D8 (artery of the lumbar enlargement or great radicular artery of Adamkiewicz); the four posterior ones were at D6, D8, D9, and D12 respectively. No alterations were noted in the radicular arteries.

Spinal arteries The anterior spinal artery was large at the D3, D4 level, then grew progressively thinner as far as D9, where it became large again. It did not show any alteration throughout its length. The wall of the intraspinal arteries was moderately thick and showed hyaloid degeneration.

Nervous tissue There were numerous recent small perivascular haemorrhages, and no ischaemic alteration.

CASE 2 C.E., a 78-year-old woman, had been hypertensive for several years, with frequent episodes of pulmonary oedema. A right hemiparesis developed over three days. There was a systolic bruit at the apex, and an electrocardiographic pattern of 'right hypertrophy'. She died on the second day after rapid worsening of symptoms.

Pathological data (Necropsy no. 17269) A moderate degree of aortic atherosclerosis was found and dilatation of the heart. There was marked atherosclerosis of the cerebral arteries. Diffuse atrophy of the gyri was observed, chiefly in the parieto-temporal areas of both hemispheres, with marked external hydrocephalus.

The spinal cord was examined from segment D2 downwards.

Radicular arteries Three anterior ones were at D5, D10, and D12 (artery of the lumbar enlargement) and three posterior ones at D5, D6, and D12. In all the radicular arteries we found diffuse hyalinosis of the wall.

Spinal arteries The anterior spinal artery tapered off down to D9, increasing in size in the underlying segments. The media were slightly thickened in the upper dorsal tract. Throughout the spinal cord intraspinal arteries showed a moderate degree of hyalinosis of the wall, more prominent in the D12 to L2 tract (see Fig. 1).

Nervous tissue No alterations of ischaemic type were observed.

CASE 3 R.U., aged 77 years, was a normotensive man who developed a right hemiparesis with aphasia, heralded a few days before by tingling paraesthaesias on his right arm. The ECG showed atrial fibrillation with signs of subendocardial ischaemia. Tests showed the following results: blood sugar level; $170 \mathrm{mg} / 100 \mathrm{ml}$.; blood nitrogen; $140 \mathrm{mg} / 100 \mathrm{ml}$; CSF albumin; 0.80 $\mathrm{g} / 100 \mathrm{ml}$. The left carotid angiography showed occlusion of the middle cerebral artery. Death, due to pulmonary oedema, ensued 25 days after admission.

Pathological data (Necropsy no. 17408) Severe generalized atherosclerosis was found, mainly aortic, coronary (resulting in myocardial infarction), renal (with old infarctions), and of cerebral arteries. There was extensive left fronto-parieto-temporal ischaemic softening, lung emphysema, and bronchopneumonia with pulmonary oedema.

The spinal cord was examined from D4 downwards.

Radicular arteries We found three anterior ones at D6, D8, and D9 (artery of lumbar enlargement) respectively, and three posterior ones at D7, L1, and L4 respectively. The radicular arteries were quite normal.

Spinal arteries The anterior spinal artery was thin from D6 to D12, exhibiting a thickening of the media at the anastomosis with the artery of the lumbar enlargement. The intraspinal arteries were normal. 


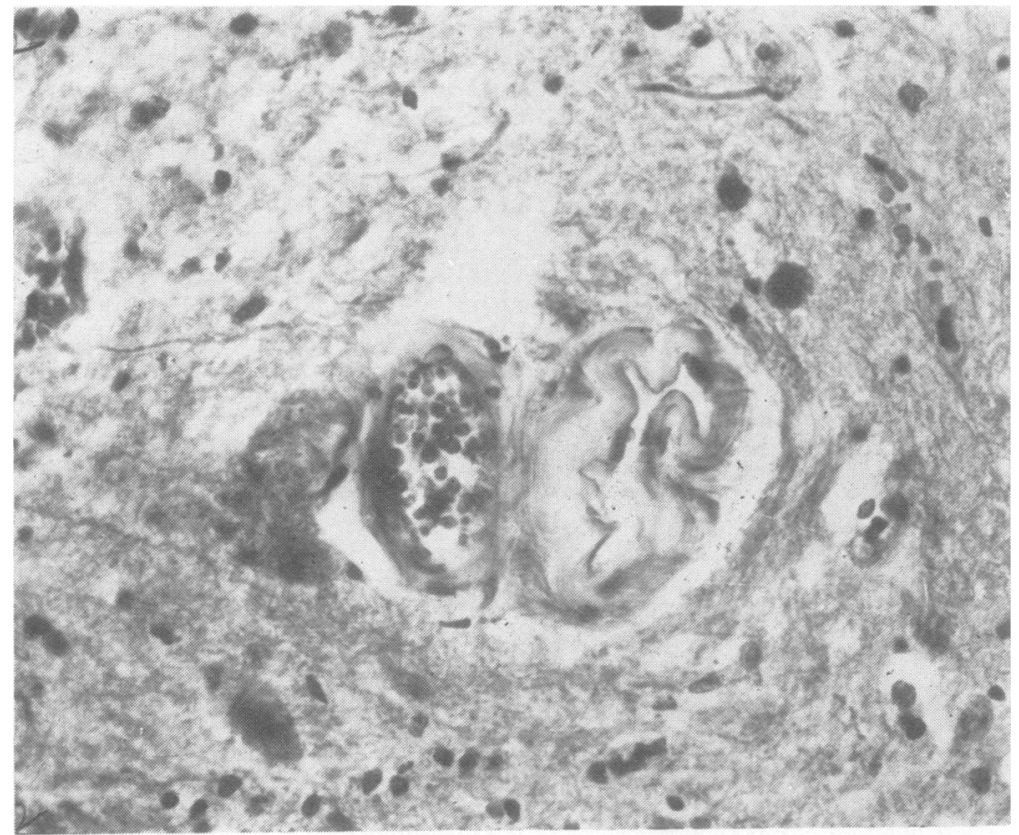

FIG. 1. Case 2. A high power view of an arteriole and $a$ venule in the grey matter of the spinal cord at S2. Note the unequal thickening prevailing in the vein. Haematoxylin and eosin, $\times 250$.

CASE 4 L.E., aged 71, a woman with severe hypertension lasting four years, had a sudden left hemiplegia. Blood nitrogen and blood sugar level were found to be normal. Blood pressure was $220 / 120 \mathrm{~mm} \mathrm{Hg}$, and ECG was normal. She died within three months from sudden cardiocirculatory failure.

Pathological data (Necropsy no. 16255) A severe generalized atherosclerosis was found in the aorta, with atheroma and dissecting aneurysm at the bifurcation, and in the cerebral arteries. There was cerebral ischaemic softening in right basal ganglia. Myocardosis and myocardiosclerosis were present. There were small abscesses at the base of the right lung.

The spinal cord was examined from D2 downwards.

Radicular arteries There were five anterior ones at D3, D5, D6, D11, and L1 (artery of the lumbar enlargement), and six posterior ones at D3, D4, D7, D10, L1, and $L 3$ respectively. All radicular arteries showed a slight degree of hyalinosis of the wall.

Intraspinal arteries The anterior spinal artery was thin along the D2 to D6 tract; with a slight thickening of the wall at $\mathrm{L} 1$ to $\mathrm{L} 2$ corresponding to the anastomosis with the artery of the lumbar enlargement. Intraspinal arteries showed at all levels thickening and hyalinosis of the wall.

Nervous tissue There were two small softenings: one at the base of a posterior horn, near the white matter of the lateral column at D5; the other at the centre of an anterior horn at the level of L2 (Figs. 2 and 3).

CASE 5 G.C., aged 64, a normotensive man, slowly developed a left hemiparesis heralded two years before by a transient paresis of his left arm. ECG showed diffuse cardiac damage. Test results were as follows: borderline blood sugar and nitrogen levels; CSF alburming $0.60 \mathrm{~g} / 100 \mathrm{ml}$; ; and Wassermann reaction positive $0 \mathrm{n}$ serum, negative on CSF. He died seven days atter admission after slow, progressive worsening of symptoons:

Pathological data (Necropsy no. 16702) There Wias severe aortic and cerebral atherosclerosis. Haemorrhagib right fronto-parietal softening was present, and lateral thrombosis of the pulmonary artery.

The spinal cord was examined from D2 downwards.

Radicular arteries There were two anterior ones at $\mathrm{D} 10$ and $\mathrm{L} 2$ respectively, and five posterior ones D4, D7, D8, D9, and L2 respectively. No true arterf of the lumbar enlargement was found (the radiculat arteries at D10 and L2 were the same size). All the radicular arteries were slightly hyalinotic.

Spinal arteries The anterior spinal artery was thm in the tract from D2 to D8 and from L4 to S2 but i wall was quite normal. Intraspinal arteries showed moderate hyalinosis with thickening of the wall, more severe in the last dorsal and first lumbar segments.

Nervous tissue No ischaemic alteration was found.

CASE 6 G.C., aged 67, was a man who had been hypęิ tensive for several years and developed a sudden right hemiplegia with aphasia, preceded three years befofe by a transient right hemiparesis. Two months before admission a lung cancer was discovered and cobalt therapy started. The ECG showed diffuse slight myocardial damage. Blood nitrogen and sugar levels wete normal. CSF and urine examinations also proved normat He died on the twelfth day from cardiocirculato
failure.

Pathological data (Necropsy no. 16436) Seve 


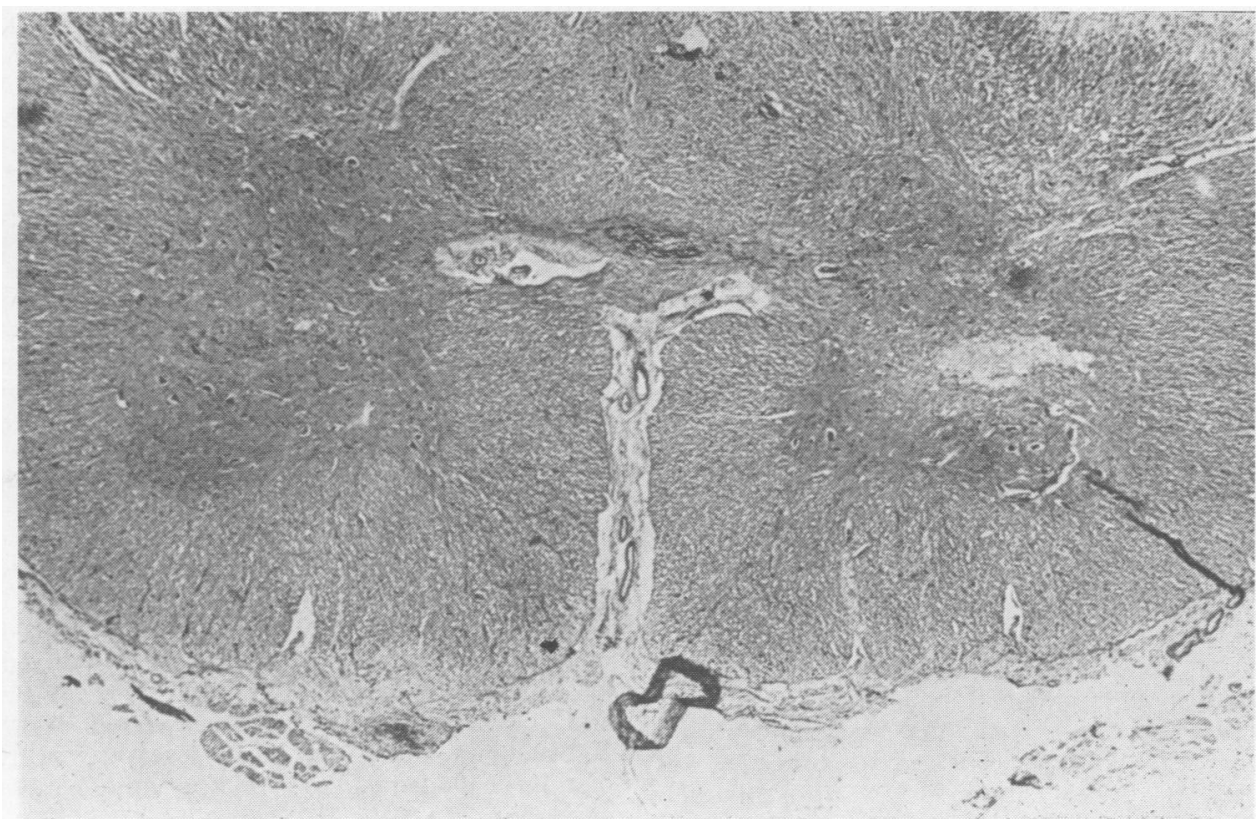

FIG. 2. Case 4. In the grey matter of an anterior horn at L2 a fairly circumscribed area of softening is visible. Haematoxylin and eosin, $\times 12$.

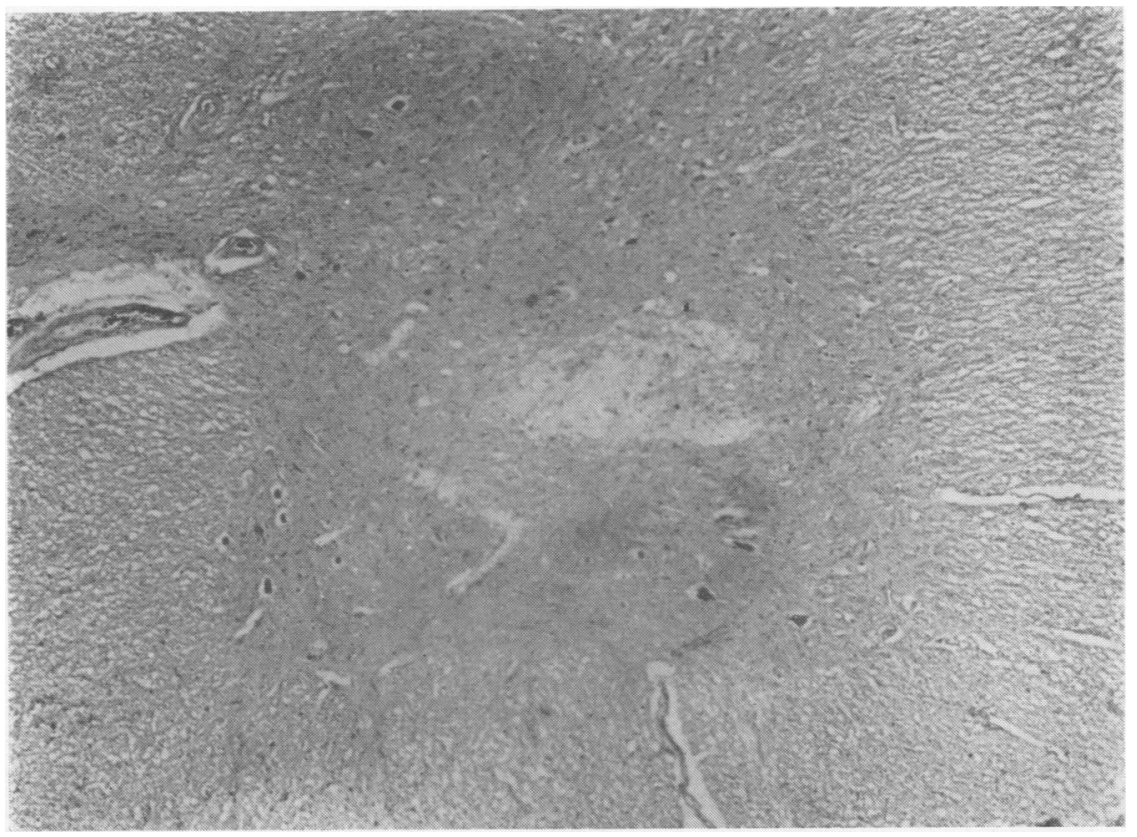

FIG. 3. Case 4.

A higher magnification of the same lesion as in Fig. 2 in a section a few millimetres lower. The remaining framework of the tissue and the poor glial reaction can be appreciated. Haematoxylin and eosin, $\times 24$. 
generalized atherosclerosis of the aorta with dissecting aneurysm of the lumbo-sacral tract, of the coronary arteries with slight sclerosis of myocardium, and of the cerebral arteries with left fronto-parieto-temporal ischaemic softening were found. Carcinoma of the lower lobe of the left lung was present.

The spinal cord was examined from segment C8 downwards.

Radicular arteries There were three anterior ones at D4, D6, and D8 (artery of the lumbar enlargement), and seven posterior ones at D2, D6, D8, D9, D10, D12, and $L 5$. All radicular arteries were quite normal.

Spinal arteries The anterior spinal artery was very thin along the D2 to D6 tract and the lumbar and sacral part of the cord; its wall was normal throughout its length. In the last dorsal and first lumbar segments the intraspinal arteries showed a slight degree of thickening of the wall.

Nervous tissue At the base of a posterior horn at the level of $\mathrm{C} 8$ there was a small softening.

CASE 7 C.A., a man aged 82, had been severely hypertensive for five years and had suffered several attacks of cardiac asthma. He was admitted for a sudden right hemiparesis with aphasia. His blood pressure was $240 / 95 \mathrm{~mm} \mathrm{Hg}$. ECG showed total atrioventricular block with atrial and ventricular extrasystoles, myocardial ischaemia. He died on the twelfth day after admission from cardiocirculatory failure.

Pathological data (Necropsy no. 16749) The findings were of severe generalized atherosclerosis of the aorta, of coronary arteries with a scar from previous infarction in the myocardium of the left ventricle, and of the cerebral arteries with a right fronto-parietal ischaemic softening.

The spinal cord was examined from C8 downwards.

Radicular arteries There were four anterior ones at D4, D8, D12 (artery of the lumbar enlargement), and S1 levels respectively, and three posterior ones at D4, D7, and D8. There was very slight thickening of the wall of all radicular arteries.

Spinal arteries The anterior spinal artery showed neither narrow portions nor alterations of the wall throughout its length. The intraspinal arteries showed, on the contrary, a hyaline thickening of the wall mainly in the lower dorsal segments.

Nervous tissue At C8 a small softening at the base of the lateral horn was found.

CASE 8 C.A., a man aged 66, had been hypertensive for many years with systolic pressure of about $250 \mathrm{~mm} \mathrm{Hg}$. He was admitted for a left hemiparesis. Blood pressure was $180 / 120 \mathrm{~mm} \mathrm{Hg}$; blood nitrogen level, $76 \mathrm{mg} / 100$ ml.; sugar level normal. In the urine hyaline-granular cylinders and red corpuscles were found. He died suddenly from myocardial infarction two months after admission.

Pathological data (Necropsy no. 16872) There was generalized atherosclerosis of the aorta and its major branches, of the kidneys with nephrosclerosis, of the coronary arteries with myocardial infarction, and of the cerebral arteries with ischaemic right fronto-parietal softening. Hypertrophy of the left ventricle was present, and a recent thrombosis of the pulmonary artery.

The spinal cord was examined from C8 downwards.

Radicular arteries There were eight anterior ones ato D1, D2, D3, D5, D8, D9, D10 (artery of the lumbarc enlargement), and $\mathrm{L} 4$, and six posterior ones at $\mathrm{D} 2 \mathrm{C}$ D4, D5, D6, D7, and D10. A hyaline thickening of the wall was present in all radicular arteries, this changes was more marked at D9, D10 levels.

Spinal arteries The anterior spinal artery was thin in the tract $C 8$ to D1 and from D6 to D9; its wall was quite? normal throughout its length. Hyalinosis with thickening $\vec{r}$ of the wall of the intraspinal arteries, more pronounced $\stackrel{\text { s? }}{+}$ in the lower dorsal segments (D9 to D12) and in the sacra? ones was observed.

Nervous tissue No ischaemic changes were found.

CASE 9 C.C., aged 76, a hypertensive woman with systolic pressure around $200 \mathrm{~mm} \mathrm{Hg}$, who 10 yearsbefore had a right hemiparesis with aphasia partially. regressed, was admitted for a new attack of right hemi $\vec{\omega}$ paresis with aphasia. ECG showed atrial fibrillation and diffuse myocardial damage. Blood pressure was $200 / 100 \mathrm{~mm} \mathrm{Hg}$; blood sugar level was normal. She died from sudden cardiocirculatory failure 15 days afteriw admission.

Pathological data (Necropsy no. 16833) There severe generalized atherosclerosis of the aorta, coronary arteries with sclerosis of the myocardiu㑲, and of cerebral arteries with ischaemic left fronto-parietaP softening. Also present were hypertrophy and dilatation of the right atrium and ventricle, recent thrombogiso of the left auricle, osteitis deformans of Paget, and lateral bronchopneumonia.

The spinal cord was examined from D1 downwards.

Radicular arteries There were anterior ones D4, D8, D10 (artery of the lumbar enlargement), and L1 levels respectively, and five posterior ones at D1, D2, D7, D9, and D11 respectively. A slight diffuse hyalinosis of the wall of the radicular arteries was found

Spinal arteries The anterior spinal artery was of normal size and appearance throughout its length. In all segments we found a moderate degree of hyalinosisō of the wall of intraspinal arteries, without any difference at various levels.

Nervous tissue No ischaemic alteration was observedo

CASE 10 B.E., aged 64, a hypertensive man who had had a Wallenberg's syndrome three years before, wasi admitted for a right hemiparesis which developed slowly? over two weeks. Blood pressure was $180 / 105 \mathrm{~mm} \mathrm{Hg} \hat{\varnothing}$ Blood sugar and nitrogen levels were borderline. He 3 died from acute pulmonary oedema 30 days after $\mathrm{O}$
admission.

Pathological data (Necropsy no. 17573) The find ings were as follows: severe generalized atherosclerosis․ㅡ. of the aorta, of the coronary arteries, of the cerebrah arteries with recent left ischaemic fronto-temporal softening, and old softening of the left cerebellar hemis $\Omega$ phere; hypertrophy of the left ventricle; broncho-N pneumonia in the right lower lobe; pulmonary oedema. 


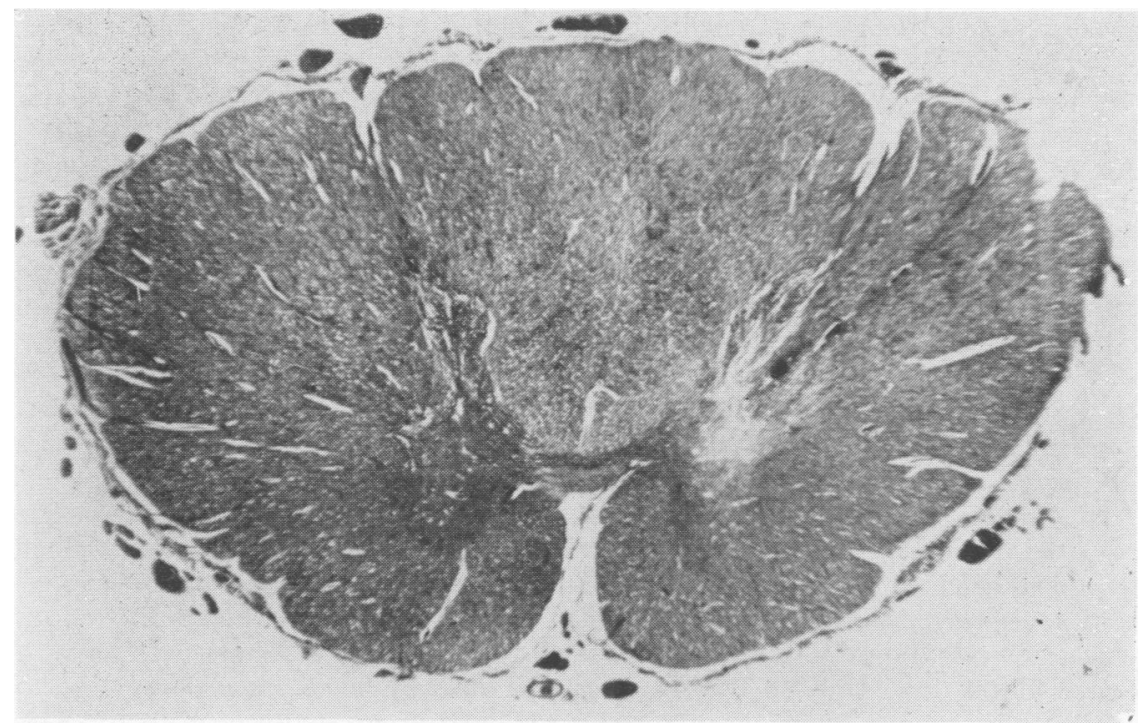

FIG. 4. Case 10.

Two different magnifications of the largest ischaemic lesion we could find are shown in Figs. 4 and 5. This softening was placed in D5 and included the whole lateral and the base of the anterior horn of the spinal cord. Haematoxylin and eosin, $\times 8$.

The spinal cord was examined from metamer $\mathrm{C7}$ downwards.

Radicular arteries There were three anterior ones at C8, D3, and L2 (artery of the lumbar enlargement), and five posterior ones at C8, D2, D3, D7, and D8 respectively.

Spinal arteries The anterior spinal artery was narrow in the D3 to D7 tract, its wall was otherwise quite normal throughout its length. The intraspinal arteries showed hyalinosis of their wall and relative thickening at every level of the spinal cord, but especially in the lower half of the dorsal cord from D6 to D12.

Nervous tissue At D5 level a softening of a lateral horn and of the base of an anterior horn was present (Figs. 4 and 5).

\section{SUMMARY OF PATHOLOGICAL LESIONS}

The main features of the pathological lesions can be summarized as follows.

FREQUENCY In one case we found two distinct lesions, one lesion in four cases, and none in five.

SITE Longitudinally, we found two lesions at C8 level (over the four cases in which we were able to examine the last cervical segment); two lesions at D5; one lesion at L2; one lesion in the sacral cord. Transversely, all the lesions were located in the grey matter-namely, three at the base of the anterior and lateral horn, one at the base of a posterior horn, and two in the centre of an anterior horn.

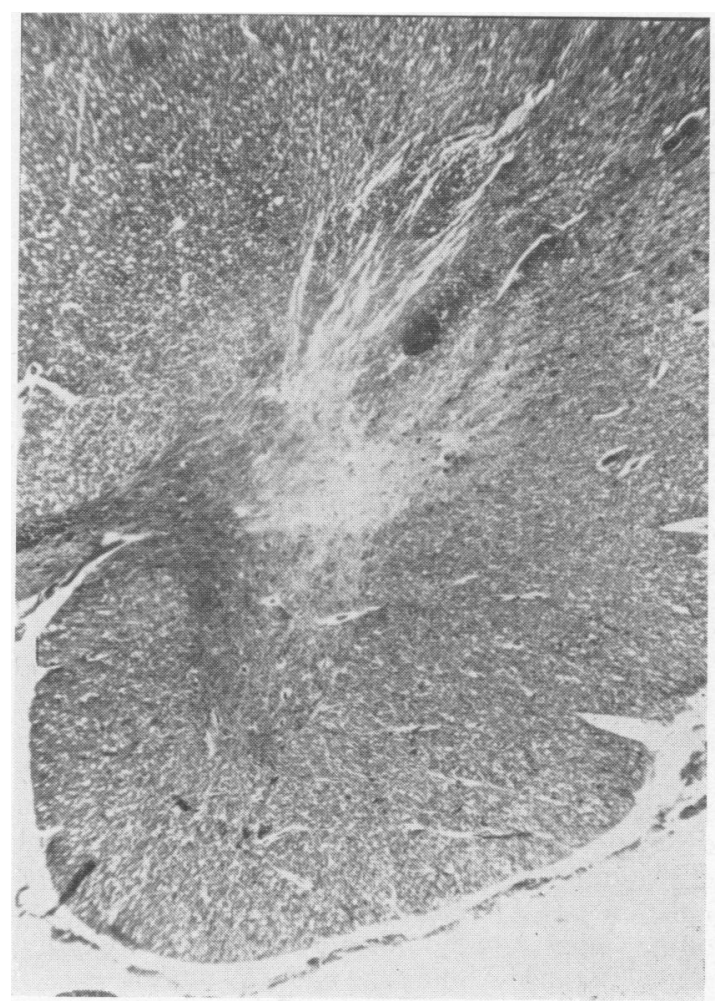

FIG. 5. Detail of Fig. 4. Haematoxylin and eosin, $\times 16$. 
DIMENSIONS The transverse extension of the malacic foci varied from $100 \mu$ to $1 \mathrm{~mm}$, and of the longitudinal one from $200 \mu$ to $1 \mathrm{~mm}$.

MICROSCOPIC FEATURES All the lesions were characterized by rarefaction of the nervous tissue with loss of cell bodies, weak staining (checked in repeated preparations), and moderate or absent glial reaction. The demarcation from the surrounding normal tissue was usually fairly clear cut.

RELATIONSHIPS WITH ATHERO- AND ARTERIOSCLEROSIS In nearly all of these cases severe generalized atherosclerotic changes of the aorta and its main branches were present: the changes mostly consisted of vast ulcerated atheromatous plaques with overlying thrombosis and of calcified plaques; in two cases there was also a dissecting aneurysm of the abdominal aorta, which, however, presumably did not affect the spinal cord blood flow. Only in one case were the atherosclerotic changes fairly limited.

Radicular arteries were spared by sclerotic changes in four cases. When they were affected, however, the alteration consisted only of thickening of the wall without evident stenosis. In one of these cases the change was more marked at the lower dorsal level; in the remaining five there was no particular location, the arteries being equally affected at all levels. The anterior spinal artery in seven out of 10 cases did not show any important mural change. In two cases there was no homogeneous thickening of the media, without stenosis of the lumen at the junction with the artery of the lumbar enlargement (Adamkiewicz's large radicular artery), and in one case such thickening was limited to the upper dorsal segments. On the contrary, we could observe more frequently alterations of the intraspinal arteries and arterioles (nine cases). Changes chiefly consisted of hyalinosis of the media. The thickening was usually moderate, being in five cases fairly modest, rather relevant in four, with subsequent reduction of the lumen.

Malacic centres were observed in three out of four cases, with consistent hyalinosis of the intraspinal vessels in two out of the remaining six cases. As for the distribution of the changes of the intraspinal vessels, these were rather uniform in three cases, while in the other cases they were unevenly distributed, usually prevailing at the dorso-lumbar junction. The location of the ischaemic lesions of the spinal cord did not show any definite relationship with the prevailing site of the hyalinosis.

DISTRIBUTION OF THE LESIONS IN RELATION TO THE AREAS OF VASCULARIZATION According to the schemes of Gillilan (1958) and Clemens (1967), 으 on the transverse section of the cord there can be $\mathbb{D}$ seen the following areas: (1) area of the central $\frac{\bar{C}}{2}$ arteries (branches of the anterior spinal artery); (2) anterior peripheral area supplied by perforating arteries coming from that part of the superficial $D$ network which is supplied by the anterior spinal artery; (3) posterior area, the blood flow of which is provided by penetrating branches arising from the posterior spinal arteries.

We found five lesions in the area supplied by $\overrightarrow{\vec{D}}$ central arteries, while just one of the lesions was located in a borderline area, between the territories supplied by the central and posterior arteries.

As to the longitudinal distribution, the lesions were never strictly located to the segments defined by Zülch as 'Grenzzonen' or 'Wasserscheide' (water- के sheds)-that is, D4 and L1. Even when the lesions $\overrightarrow{0}$ could be found in an adjacent segment (D5 case 4, D5 case 10, L2 case 4) they were usually close to $\vec{\omega}$ an anterior radicular artery that was located at D5, D3, and L1 respectively.

\section{DISCUSSION}

In five out of 10 elderly atherosclerotic subjecto $\infty$ who had died from ischaemic brain lesions ws found small recent spinal cord softenings. In a cases the lesions consisted of rarefaction of tissue $\frac{7}{2}$ with loss of neurones and poor staining (spongo dissolution). The longitudinal extension of the $\vec{\theta}$ lesions was greater than their transverse one They were mainly located in the lower cervical and middle dorsal tract, in the grey matter, and more often in the centre or at the base of the anterior horns. These data agree with the findings of Jellinger and Neumayer $(1962 \mathrm{a}, \mathrm{b})$ of small softenings in the anterior horns, chiefly in the cervical enlargement. According to Mannen (1963), other preferential sites of small ischaemic foci are the fourth and fifth cervical segments. We cannot comment on this statement, our examination being limited to the lower cervical, dorsal, and lumbosacral tract of the spinal cord. The small softenings were more frequent in our material than in Mannen's. In fact he found circumscribed ischaemic lesions in the grey matter of the cord in $8.3 \%$ of unselected $\delta$ elderly subjects. It should be pointed out, however, that in our cases the examination was carried out 의 on semi-seriated histological preparations (two sections every $150 \mu$ ) and that our material consisted of cases with severe circulatory involvement.

The sclerosis of radicular arteries and of the $\mathscr{N}$ peri- and intraspinal arterial network was nearly $\tilde{O}$ always of moderate degree. Conceivably, the N systemic cardiocirculatory situation, particularly 
the circulatory disturbances shown by these patients before death, and the high degree of atherosclerosis of the great arteries were relevant to the production of the softenings. These factors undoubtedly can account for hypoxia, but not for the particular location of the ischaemic changes. We think that the ischaemic damage occurred in an area particularly prone to ischaemia, perhaps because of the features of its arterial network.

Zülch (1954) described in the spinal cord some areas which would be more liable to ischaemia in conditions of systemic circulatory failure. These are the border-areas (Grenzzonen) between the different vascular districts, located both transversely (between the area of the central arteries and that of the peripheral ones) and longitudinally (particularly at D4 level-namely, between the territories of the aorta and vertebral arteries. According to Zülch, this schematization is valid only when the afferent arterial network is composed of few significant radicular arteries ('minimal blood supply').

In our cases only one of the lesions was located in a border-area of Zülch. In fact most ischaemic areas were in the central artery's territory-namely, in the anterior horns or at its base-and in the cervical and lumbosacral enlargements.

Alternatively, ischaemic spinal foci might be due to occlusion of small arterial branches. Fisher (1965) put forward this hypothesis to account for the so-called 'lacunae'-that is, circumscribed ischaemic areas of a few millimetres in diameter, which are often asymptomatic, usually found in the basal ganglia of arteriosclerotic subjects with hypertension. Occlusion might be due to thrombosis brought about by circulatory slowing or to a smallsized embolus. In severe atherosclerotic patients embolic material to spinal arteries may originate from an ulcerated plaque, or from a mural thrombus at the origin of the intercostal arteries from the aorta or of the radicular arteries from the vertebrals. Although we did not observe occlusions even in the arteries of small calibre afferent to the ischaemic areas, this does not rule out the occlusive hypothesis.

In conclusion, our data provide indirect confirmation of Jellinger and Neumayer's thesis that some neurological pictures observed in elderly atherosclerotic subjects with signs of anterior horn involvement are caused by small foci of ischaemic necrosis in the spinal cord.

\section{SUMMARY}

Six small recent spinal cord softenings were found in five out of 10 elderly subjects with severe atherosclerosis who had died from ischaemic brain lesions.
The ischaemic foci of the spinal cord were located in the grey matter, in the centre or at the base of the anterior horns, at C8, D5, L2, and sacral levels.

No clear-cut relationships were found between the site of the lesions and either the position of the radicular arteries or the size and degree of atherosclerotic changes of the afferent arterial network.

Despite an accurate microscopic examination, no occlusion of the intraparenchymal arteries related to the ischaemic foci was found.

This study supports previous observations of small ischaemic necroses in the grey matter of the spinal cord in elderly arteriosclerotic patients, leading to clinical syndromes of nuclear amyotrophy consequent on vascular myelopathy in old age.

\section{REFERENCES}

Bailey, A. A. (1953). Changes with age in the spinal cord. Arch. Neurol. (Chic.), 70, 299-309.

Bartsch, W. (1961). Klinik der spinalen Durchblutungstörungen. Acta Neurochir. (Wien). Suppl. VII, 255-260.

Clemens, H. J. (1967). Beitrag des Morphologen zum Problem der spinalen Mangeldurchblutung. Verh. dtsch. Ges. unn. Med., 72, 1059-1080.

Corbin, J. L. (1961). Anatomie et Pathologie Artérielles de la Moelle. Masson: Paris.

Dejerine, J. (1906). Sur la claudication intermittente de la moelle épinière. Rev. neurol., 14, 341-350.

Demange, E. (1884). Contribution à l'étude des scléroses médullaires d'origine vasculaire. Rev. Méd. (Paris), 4, 753-766.

Fazio, C. (1969). Vascular pathology of the spinal cord. In Pathology of the Nervous System, vol. 2. Edited by Jeff Minckler. McGraw-Hill: New York.

Fieschi, C. and de Carolis, V. (1962). Étude sur l'existence et sur la distribution de lésions ischémiques de la moelle épinère dans un groupe de malades morts par apoplexie cérébrale. Rev. neurol., 106, 712-715.

_- and Gottlieb, A. (1967). Lesioni ischemiche nella sostanza grigia del midollo spinale di soggetti arteriosclerotici. Atti del XVI Congresso Nazionale di Neurologia (Rome), 3, 206-208.

Fisher, C. M. (1965). Lacunes: Small, deep cerebral infarcts. Neurology (Minneap.), 15, 774-784.

Garcin, R., and Gruner, J. (1953). Nécrose cavitaire des cornes antérieures de la moelle au cours d'un syndrome réalisant une form pseudo-polynévritique de sclérose latérale amyotrophique. Presse méd., 62, 1723-1724.

Gillilan, L. A. (1958). The arterial blood supply of the human spinal cord. J. comp. Neurol., 110, 75-103.

Guizzetti, P. (1924). In Trattato di anatomia patologica di Foà. UTET: Torino.

Jellinger, K. (1966). Zur Orthologie und Pathologie der Rückenmarksdurchblutung. Springer: Wien.

Neumayer, E. (1962). Myélopathies progressives d'origine vasculaire. Rev. neurol., 106, 666-669.

- - (1962b). Myélopathie progressive d'origine vasculaire. Contribution anatomoclinique aux syndromes d'une hypovascularisation chronique de la moelle. Acta neurol. belg., 62, 944-955.

Lanza, G. (1938). Studio sistematico sull'arteriosclerosi del cervello e del midollo spinale (con particolare riguardo ai rapporti con l'arteriosclerosi degli altri parenchimi e con le emorragie ed i rammollimenti cerebrali). Arch. ital. Anat. Istol. Pat., 9, 259-337.

Lhermitte, J. J. (1907). Etude sur les Paraplégies des Vieillards. Imprimerie de la Cour d'Appel, Thèse de Paris.

Marie, P., and Foix, Ch. (1912). L'atrophie isolèe non progressive des petits muscles de la main. Fréquence relative et pathogénie. Téphromalacie antérieure. Polyomyélite, névrite radiculaire ou non radiculaire. Nouv. Iconogr. Salpêt., 25, 353-363.

Mannen, T. (1963). The vascular lesions in the spinal cord of the aged. Clin. Neurol., Japan, 3, 47-63. 
Neumayer, E. (1955). Veränderungen am Rückenmark im Senium bei einem der amyotrophischen Lateralsclerose ännlichen klinischen Bild. Wien. Z. Nervenheilk, 11, 196-206.

Sarteschi, P., and Giannini, A. (1960). La patologia vascolare del midollo spinale. Giardini: Pisa
Zülch, K. J. (1954), Mangeldurchblutung an der Grenzzone zweier Gefässgebiete als Ursache bisher ungeklärter Rückenmarksschädigungen. Dtsch. Z. Nervenheilk, 172, 81-101.

(1962). Réflexions sur la physiopathologie des troubles vasculaires médullaires. Rev. neurol., 106, 632-645. 